\title{
PULMONARY RETRANSPLANTATION: DOES THE INDICATION FOR OPERATION INFLUENCE POSTOPERATIVE LUNG FUNCTION?
}

Richard J. Novick, MD

Larry Stitt, MSc

Hans-Joachim Schäfers, MD

Bernard Andréassian, MD

Jean-Pierre Duchatelle, MD

Walter Klepetko, MD

Robert L. Hardesty, MD

Adaani Frost, MD

G. Alexander Patterson, MD
Objectives: An international series of pulmonary retransplantation was updated to determine the factors associated with pulmonary function, bronchiolitis obliterans syndrome stage, and survival after operation. Methods: One hundred sixty patients underwent retransplantation in 35 centers from 1985 to 1995. Logistic regression methods were used to determine variables associated with 3-month and 2-year survival after retransplantation. Values of forced expiratory volume in 1 second were contrasted between groups by unpaired, two-tailed $t$ tests. Results: The median follow-up in surviving recipients was 780 days. Actuarial survival was $45 \% \pm 4 \%, 41 \% \pm 4 \%$, and $33 \% \pm 4 \%$ at 1,2 , and 3 years, respectively. On multivariable analysis, the only predictor of 3-month survival was preoperative ambulatory status $(p=0.005)$, whereas center experience with at least five pulmonary retransplantations was the sole predictor of 2-year survival $(p=0.04$ ). The prevalence of stage 3 (severe) bronchiolitis obliterans syndrome was $12 \%$ at 1 year, $15 \%$ at 2 years, and $33 \%$ at 3 years after retransplantation. Retransplant recipients with stage 3 bronchiolitis obliterans syndrome at 1 year had a significantly worse actuarial survival than those with stages 0 to $2(p<0.01)$. By 3 years after retransplantation, the forced expiratory volume in 1 second was significantly lower in patients who underwent reoperation because of obliterative bronchiolitis than in patients who underwent retransplantation because of acute graft failure or an airway complication $(p=0.02$ ). Only $31 \%$ of patients who underwent retransplantation because of obliterative bronchiolitis were free of bronchiolitis obliterans syndrome at 3 years versus $83 \%$ of patients who underwent retransplantation because of other indications $(p=0.02)$. Conclusions: Preoperative ambulatory status predicts early survival and center volume predicts intermediate-term outcome after retransplantation. Improved management strategies are necessary to prevent the development of progressive graft dysfunction after retransplantation for obliterative bronchiolitis. (J Thorac Cardiovasc Surg 1996;112:1504-14)
From the Departments of Surgery and Epidemiology and Biostatistics, the London Health Sciences Centre, the Robarts Research Institute, and the University of Western Ontario, London, Ontario, Canada; Hannover, Germany; Clichy, France; Vienna, Austria; Pittsburgh, Pa.; Houston, Tex.; St. Louis, Mo.; and participating centers in the pulmonary retransplant registry.

Supported by grants from the Ontario Thoracic Society, the Multi-Organ Transplant Service, London Health Sciences Center, and Sandoz Canada, Inc.

Read at the Seventy-sixth Annual Meeting of The American Association for Thoracic Surgery, San Diego, Calif., April 28--May 1, 1996.

Received for publication May 6, 1996; revisions requested June 26, 1996; revisions received July 22, 1996; accepted for publication July 26, 1996.

Address for reprints: Richard J. Novick, MD, P.O. Box 5339, London Health Sciences Centre, London, Ontario, Canada N6A 5A5.
D espite significant advances in donor management $^{1}$ and lung graft preservation ${ }^{2}$ in recent years, the number of reported lung transplantation procedures has plateaued since $1993 .{ }^{3 *}$ Although the results of primary lung transplantation have improved, ${ }^{4}$ lung transplant recipients remain vulnerable to severe early graft dysfunction, intractable airway healing problems, and obliterative bronchiolitis (OB). Since the late 1980 s an increasing number of pulmonary retransplantations have been per-

*Cooper JD, St. Louis International Lung Transplant Registry. September 1995 report. St. Louis, Missouri.

Copyright (c) 1996 by Mosby-Year Book, Inc. $0022-5223 / 96 \$ 5.00+0 \quad \mathbf{1 2 / 6 / 7 6 9 2 3}$ 
Table I. Association of recipient variables with 3-month and 2-year survival after pulmonary retransplantation

\begin{tabular}{|c|c|c|c|c|c|c|c|c|}
\hline \multirow[b]{3}{*}{ Variable } & \multicolumn{4}{|c|}{ Three-month survival } & \multicolumn{4}{|c|}{ Two-year survival } \\
\hline & \multicolumn{2}{|c|}{ Marginal analysis } & \multicolumn{2}{|c|}{ Multivariable analysis } & \multicolumn{2}{|c|}{ Marginal analysis } & \multicolumn{2}{|c|}{ Multivariable analysis } \\
\hline & $\begin{array}{c}\text { Odds ratio } \\
(95 \% \mathrm{CI})\end{array}$ & $p$ Value & $\begin{array}{l}\text { Adjusted } \\
\text { odds ratio } \\
(95 \% \text { CI })\end{array}$ & $p$ Value & $\begin{array}{l}\text { Odds ratio } \\
(95 \% \mathrm{CI})\end{array}$ & $p$ Value & $\begin{array}{l}\text { Adjusted } \\
\text { odds ratio } \\
(95 \% \mathrm{CI})\end{array}$ & $p$ Value \\
\hline \multicolumn{9}{|l|}{ Age } \\
\hline As a continuous variable & $*$ & 0.56 & $\uparrow$ & NS & * & 0.63 & $\dagger$ & NS \\
\hline$\leq 40$ vs $>40 \mathrm{yr}$ & $\begin{array}{c}1.23 \\
(0.66,2.31)\end{array}$ & 0.52 & $\dagger$ & NS & $\begin{array}{c}1.09 \\
(0.45,2.04)\end{array}$ & 0.92 & $\dagger$ & NS \\
\hline Female sex & $\begin{array}{c}0.90 \\
(0.48,1.69)\end{array}$ & 0.73 & $\dagger$ & NS & $\begin{array}{c}1.35 \\
(0.64,2.87)\end{array}$ & 0.44 & $\dagger$ & NS \\
\hline \multicolumn{9}{|l|}{$\begin{array}{l}\text { Indication for retransplanta- } \\
\text { tion }\end{array}$} \\
\hline All indications & $*$ & 0.42 & $\dagger$ & NS & $*$ & 0.44 & $\dagger$ & NS \\
\hline OB vs non-OB & $\begin{array}{c}1.36 \\
(0.72,2.57)\end{array}$ & 0.34 & $\dagger$ & NS & $\begin{array}{c}0.69 \\
(0.33,1.46)\end{array}$ & 0.33 & $\dagger$ & NS \\
\hline $\begin{array}{l}\text { Ambulatory before retrans- } \\
\text { plantation }\end{array}$ & $\begin{array}{c}2.42 \\
(1.19,4.95)\end{array}$ & 0.01 & $\begin{array}{c}2.97 \\
(1.37,6.40)\end{array}$ & 0.005 & $\begin{array}{c}1.61 \\
(0.72,3.61)\end{array}$ & 0.25 & $\dagger$ & NS \\
\hline $\begin{array}{l}\text { Ventilator support before } \\
\text { retransplantation }\end{array}$ & $\begin{array}{c}0.64 \\
(0.34,1.21)\end{array}$ & 0.17 & $\dagger$ & NS & $\begin{array}{c}0.94 \\
(0.44,2.00)\end{array}$ & 0.87 & $\dagger$ & NS \\
\hline Recipient CMV positivity & $\begin{array}{c}0.72 \\
(0.36,1.45)\end{array}$ & 0.36 & $\dagger$ & NS & $\begin{array}{c}0.96 \\
(0.41,2.22)\end{array}$ & 0.92 & $\dagger$ & NS \\
\hline \multicolumn{9}{|l|}{ Waiting time } \\
\hline As a continuous variable & $*$ & 0.62 & $\dagger$ & NS & * & 0.41 & $\dagger$ & NS \\
\hline$>2$ wk vs $\leq 2 \mathrm{wk}$ & $\begin{array}{c}1.45 \\
(0.74,2.86)\end{array}$ & 0.28 & $\dagger$ & NS & $\begin{array}{c}1.22 \\
(0.55,2.73)\end{array}$ & 0.62 & $\dagger$ & NS \\
\hline \multicolumn{9}{|l|}{ Interval between transplants } \\
\hline Continuous & * & 0.05 & $\dagger$ & NS & $*$ & 0.76 & $\dagger$ & NS \\
\hline$>2 \mathrm{yr}$ vs $\leq 2 \mathrm{yr}$ & $\begin{array}{c}1.79 \\
(0.82,3.89)\end{array}$ & 0.15 & $\dagger$ & NS & $\begin{array}{c}1.07 \\
(0.33,2.62)\end{array}$ & 0.90 & $\dagger$ & NS \\
\hline
\end{tabular}

Odds ratios and adjusted odds ratios $>1.0$ indicate increased survival, whereas ratios $<1.0$ indicate decreased survival at 3 months and 2 years after retransplantation. $C I$, confidence interval; $N S$, not significant on multivariable analysis; $C M V$, cytomegalovirus; $O B$, obliterative bronchiolitis.

* Odds ratio not calculated because variable has more than two categories.

$\uparrow$ Adjusted odds ratio not calculated because variable does not enter into multivariable model.

formed because of acute or chronic graft failure..$^{5-14}$ In view of the marked scarcity of suitable donor lung grafts, the pulmonary retransplant registry was established in 1991 with the goal of determining, via a multiinstitutional analysis, the outcome and predictors of survival after pulmonary retransplantation. ${ }^{5}$ Recently, with an increasing duration of follow-up in retransplant recipients, the registry has focused on pulmonary function and clinical status in the intermediate term after operation. ${ }^{8}$ After a significant number of patients reached the third and fourth anniversaries of retransplantation, the registry data were updated to determine the recurrence rate of $O B$ and the factors associated with survival and pulmonary function in the intermediate term after retransplantation.

\section{Patients and methods}

During the past 5 years patients undergoing pulmonary retransplantation have been recruited to the registry by means of a standardized study questionnaire. Patients who have undergone repeat heart-lung transplantation or a heart-lung transplantation after a previous pulmonary transplantation have been excluded. ${ }^{5}$ Once registered, all patients are followed up prospectively, with 6- to 12 month updates of clinical status and pulmonary function. For the purposes of this report, the status of all registry patients was updated in October 1995. Patients who underwent retransplantation for any indication were included in the study cohort.

The 17 variables listed in Tables I and II were recorded for each patient. An ambulatory recipient was defined as a patient who was able to walk at least 50 meters, with or without assistance, immediately before retransplantation. Study form results were incorporated into the pulmonary retransplant database with the use of the FoxPro database 
Table II. Association of donor and operative variables with 3-month and 2-year survival after pulmonary retransplantation

\begin{tabular}{|c|c|c|c|c|c|c|c|c|}
\hline \multirow[b]{3}{*}{ Variable } & \multicolumn{4}{|c|}{ Three-month survival } & \multicolumn{4}{|c|}{ Two-year survival } \\
\hline & \multicolumn{2}{|c|}{ Marginal analysis } & \multicolumn{2}{|c|}{ Multivariable analysis } & \multicolumn{2}{|c|}{ Marginal analysis } & \multicolumn{2}{|c|}{ Multivariable analysis } \\
\hline & $\begin{array}{c}\text { Odds ratio } \\
(95 \% \text { CI })\end{array}$ & $p$ Value & $\begin{array}{l}\text { Adjusted } \\
\text { odds ratio }\end{array}$ & $p$ Value & $\begin{array}{c}\text { Odds ratio } \\
(95 \% \text { CI })\end{array}$ & $p$ Value & $\begin{array}{l}\text { Adjusted } \\
\text { odds ratio } \\
(95 \% \text { CI })\end{array}$ & $p$ Value \\
\hline \multicolumn{9}{|l|}{ Year of reoperation } \\
\hline As a continuous variable & $*$ & 0.04 & $\dagger$ & NS & * & 0.44 & $\dagger$ & NS \\
\hline $1993-1995$ vs $1985-1992$ & $\begin{array}{c}1.77 \\
(0.93,3.35)\end{array}$ & 0.08 & $\dagger$ & NS & $\begin{array}{c}0.91 \\
(0.43,1.92)\end{array}$ & 0.80 & $\dagger$ & NS \\
\hline \multicolumn{9}{|l|}{ Retransplantation center } \\
\hline Europe vs North America & $\begin{array}{c}1.47 \\
(0.78,2.76)\end{array}$ & 0.24 & $\dagger$ & NS & $\begin{array}{c}1.48 \\
(0.70,3.14)\end{array}$ & 0.31 & $\dagger$ & NS \\
\hline \multicolumn{9}{|l|}{ Type of reoperation } \\
\hline All 5 types & $*$ & 0.85 & $\dagger$ & NS & $*$ & 0.21 & $\dagger$ & NS \\
\hline Old graft in situ vs not & $\begin{array}{c}0.85 \\
(0.45,1.63)\end{array}$ & 0.63 & $\dagger$ & NS & $\begin{array}{c}0.54 \\
(0.23,1.23)\end{array}$ & 0.14 & $\dagger$ & NS \\
\hline \multicolumn{9}{|l|}{ Total center volume } \\
\hline$\geq 5$ vs $<5$ retransplants & $\begin{array}{c}1.92 \\
(1.00,3.72)\end{array}$ & 0.05 & $\dagger$ & NS & $\begin{array}{c}2.72 \\
(1.13,6.58)\end{array}$ & 0.03 & $\begin{array}{c}2.52 \\
(1.04,6.15)\end{array}$ & 0.041 \\
\hline \multicolumn{9}{|l|}{ Individual center experience } \\
\hline$>4$ th vs $\leq 4$ th retransplant & $\begin{array}{c}1.56 \\
(0.82,2.99)\end{array}$ & 0.17 & $\dagger$ & NS & $\begin{array}{c}1.29 \\
(0.59,2.81)\end{array}$ & 0.52 & $\dagger$ & NS \\
\hline $\begin{array}{l}\text { Identical match of donor- } \\
\text { recipient } \mathrm{ABO} \text { blood group }\end{array}$ & $\begin{array}{c}1.81 \\
(0.84,3.93)\end{array}$ & 0.13 & $\dagger$ & NS & $\begin{array}{c}1.59 \\
(0.62,4.10)\end{array}$ & 0.33 & $\dagger$ & NS \\
\hline Donor CMV negativity & $\begin{array}{c}1.71 \\
(0.89,3.28)\end{array}$ & 0.11 & $\dagger$ & NS & $\begin{array}{c}1.89 \\
(0.87,4.07)\end{array}$ & 0.10 & $\dagger$ & NS \\
\hline Donor-recipient CMV mismatch & $\begin{array}{c}0.60 \\
(0.23,1.54)\end{array}$ & 0.29 & $\dagger$ & NS & $\begin{array}{c}0.42 \\
(0.12,1.56)\end{array}$ & 0.19 & $\dagger$ & NS \\
\hline
\end{tabular}

Odds ratios and adjusted odds ratios $>1.0$ indicate increased survival, whereas ratios $<1.0$ indicate decreased survival at 3 months and 2 years after retransplantation. $C I$, confidence interval; $N S$, not significant on multivariable analysis; $C M V$, cytomegalovirus; $O B$, obliterative bronchiolitis.

*Odds ratio not calculated because variable has more than two categories.

$\uparrow$ Adjusted odds ratio not calculated because variable does not enter into multivariable model.

management system (Microsoft Corporation, Redmond, Wash.) on a Pentium/100 $\mathrm{MHz}$ computer. Statistical analysis was performed with the SAS statistical package, version 6.08 (SAS Institute Inc., Cary, N.C.). All data were expressed as mean plus or minus the standard error of the mean. Survival was calculated actuarially ${ }^{15}$ and logistic regression methods ${ }^{16}$ were used to determine which variables were associated with early ( 3 month) and intermediate-term (2 year) survival after retransplantation. Variables exhibiting a $p$ value less than 0.25 on marginal (single covariate) analysis were considered for entry into a multivariable model to determine the independent predictors of survival after retransplantation. Furthermore, the odds ratio of each variable was expressed as a comparison of survival between groups, with a value of 1.0 indicating no survival difference, a value greater than 1.0 indicating increased survival, and a value less than 1.0 indicating decreased survival after retransplantation.

A major focus of this article and our previous report ${ }^{8}$ was pulmonary function and the recurrence of bronchiolitis obliterans syndrome (BOS) after retransplantation. Complete pulmonary function test data were therefore obtained prospectively from every survivor of retransplantation at 6- to 12-month intervals. BOS stages were assigned according to previously published criteria on the basis of postoperative values of forced expiratory volume in 1 second $\left(\mathrm{FEV}_{1}\right) .{ }^{17}$ The changes in absolute $\mathrm{FEV}_{1}$ values at 1,2 , and 3 years after retransplantation were calculated for the entire study cohort, for single versus bilateral lung retransplant recipients, and for patients who underwent retransplantation because of $\mathrm{OB}$ versus those who underwent retransplantation because of other conditions. Paired, two-tailed $t$ tests were used to compare changes over time within each patient group. No adjustment was made for multiple comparisons. Descriptive comparisons between patient groups indicated that variances were unequal and the FEV data were therefore log transformed (to improve the equality of variances) before being compared by unpaired, two-tailed tests. ${ }^{18}$ In addition, contingency table analyses were used to compare the prevalence of stages 1,2, and 3 BOS between patient groups at 1, 2, and 3 years after retransplantation. A $p$ value $<0.05$ was considered significant. 


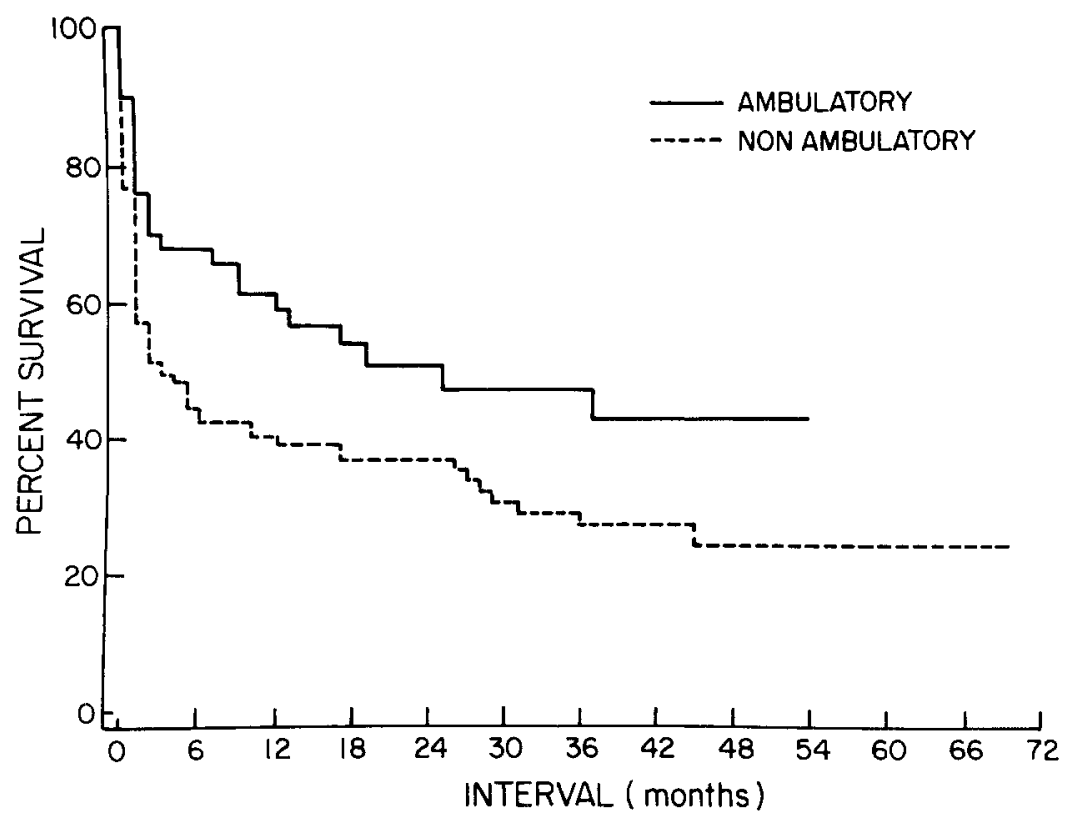

Fig. 1. Actuarial survival according to ambulatory status of recipient immediately before retransplantation: $n=51$ (ambulatory) versus 109 (nonambulatory); $p=0.01$.

\section{Results}

Thirty-five lung transplantation centers participated in this study, including 19 from North America and 16 from Europe. The study cohort comprised 160 retransplant recipients, including 92 female and 68 male patients with a median age of 42 years (range 6 months to 62 years). Before undergoing the first transplantation $31 \%$ of patients had emphysema, $20 \%$ restrictive lung disease, $20 \%$ primary pulmonary hypertension or Eisenmenger's syndrome, $17 \%$ cystic fibrosis, and $12 \%$ miscellaneous conditions. The indications for retransplantation (and median interval between transplant procedures) included $\mathrm{OB}$ in 93 cases (624 days), primary graft failure in 40 cases (13 days), intractable airway complications in 14 cases (119 days), histologically confirmed severe acute rejection in 8 cases (23 days), and miscellaneous conditions in 5 cases (206 days). Forty patients (25\%) underwent ipsilateral single-lung retransplantation, 28 patients (18\%) contralateral single-lung retransplantation, 36 patients $(23 \%)$ repeat double-lung transplantation, 25 patients $(15 \%)$ double-lung transplantation after a previous single-lung transplantation, and 31 patients (19\%) single-lung transplantation after a previous double-lung or heart-lung transplantation. Patient follow-up was $100 \%$ complete, with current survival and pulmonary function test data available in every patient.
Survival. Of the retransplant recipients, 101 have died and 59 are still living. The 1-year actuarial survival was $45 \% \pm 4 \%$ versus $35 \% \pm 5 \%$ in the first report from the retransplant registry 3 years ago. ${ }^{5}$ The 2-, 3-, and 4-year actuarial survivals were $41 \% \pm 4 \%, 33 \% \pm 4 \%$, and $30 \% \pm 4 \%$, respectively. The median follow-up in current survivors is 780 days (mean $894 \pm 74$ days, range 41 to 2113 days). Sixty-two patients have reached the first anniversary, 39 the second anniversary, 27 the third anniversary, 13 the fourth anniversary, and 3 the fifth anniversary of retransplantation.

Association of recipient variables with survival. The association of nine recipient-related variables with survival after retransplantation is shown in Table I. Survival was not significantly different according to the age, sex, original diagnosis, or cytomegalovirus status of the recipient. Similarly, survival did not differ according to the indication for retransplantation, the recipients' ventilator status before reoperation, or the official waiting time for a second lung graft. When analyzed as a continuous variable, a longer interval between operations was associated with increased 3-month, but not 2-year, survival after retransplantation. Immediately before retransplantation, only $32 \%$ of recipients were ambulatory. These patients had a significantly improved 3-month survival after retransplantation on both marginal and multivariable analyses and a 


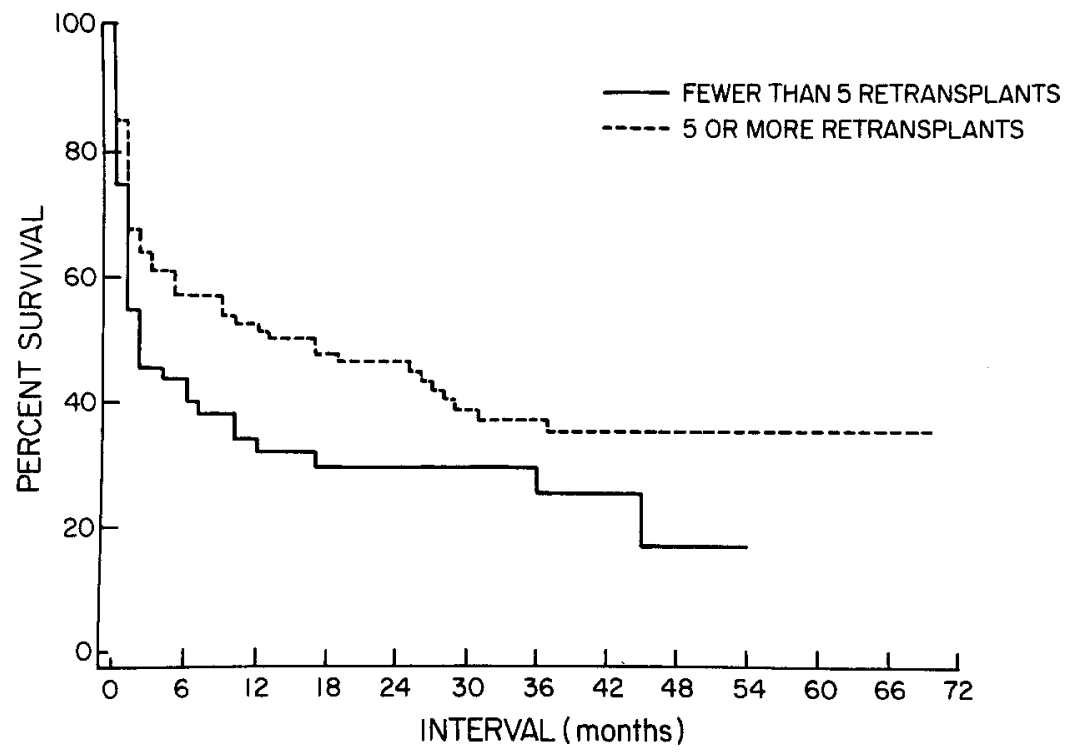

Fig. 2. Actuarial survival according to volume of retransplantation procedures done: $n=105$ ( 5 or more retransplants) versus 55 (fewer than 5 retransplants); $p=0.03$.

significantly better overall survival than nonambulatory recipients on actuarial analysis (Fig. 1). Nevertheless, on multivariable analysis no recipient variable was predictive of 2-year survival after retransplantation (Table I).

Association of donor and operative variables with survival. The association of eight donor and operative variables with survival after retransplantation is shown in Table II. When analyzed as a continuous variable, the year of retransplantation was associated with 3-month, but not 2-year, survival. The type of retransplantation procedure, location of the retransplantation center, donor cytomegalovirus status, presence of a donor-recipient cytomegalovirus mismatch, and presence of an identical match of donor-recipient $\mathrm{ABO}$ blood group did not have a significant impact on 3-month or 2-year survival after retransplantation. The total center volume of pulmonary retransplantation procedures was associated with both 3-month and 2-year survival (Table II, Fig. 2) and was the sole variable that predicted 2-year survival after retransplantation on multivariable analysis (odds ratio $2.52,95 \%$ confidence interval 1.04 to $6.15, p=0.041$ ).

Center effect. Because the data in this study were collected from 35 North American and European centers, there was a possibility that these data might be clustered. An adjusted logistic regression analysis was therefore performed, comparing the survival among larger centers with five or more patients who underwent transplantation versus that in smaller centers with fewer than five retransplant recipients. For 90-day postoperative survival, the adjusted analysis did not significantly change the odds ratios, confidence intervals, and $p$ values of the 17 variables shown in Tables I and II. For 2-year survival, however, the adjusted analysis disclosed that center of retransplantation had a significant effect. The adjusted multivariable analysis also resulted in ambulatory status becoming a significant predictor of 2-year survival (odds ratio 2.99, 95\% confidence interval 1.10 to $8.09, p=0.03$ ), whereas ambulatory status was not a significant predictor of 2-year survival in Table I. Aside from ambulatory status, no new variable became significant in the adjusted analysis of center effect.

Causes of death. Consonant with previous reports from the registry, ${ }^{5-8}$ opportunistic infection was the leading cause of death after retransplantation. Nevertheless, with increased patient accrual and maturation of the registry database, the percentage of deaths caused by infection has decreased to $42 \%$, as opposed to greater than $50 \%$ in previous reports. Concomitantly, the percentage of deaths caused by recurrent $\mathrm{OB}$ has increased to $26 \%$. An additional $26 \%$ of patients died as a result of acute failure of the second graft early after reoperation, $3 \%$ of an airway complication, and $3 \%$ of miscellaneous causes.

Functional status after retransplantation. After a median follow-up of 780 days, $53 \%$ of patients 


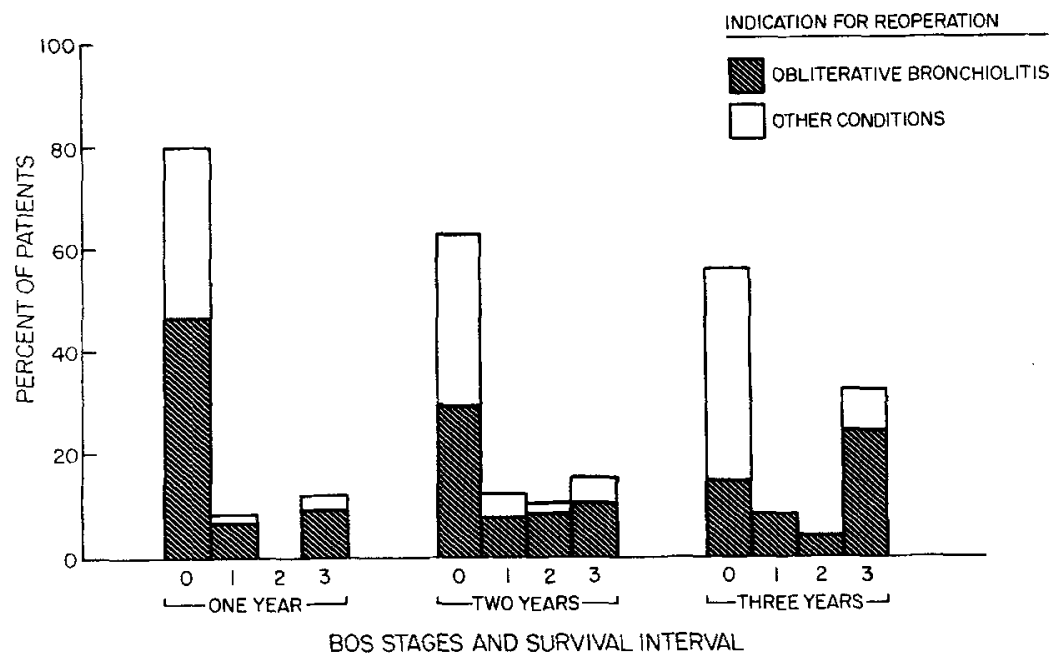

Fig. 3. Prevalence of stages $0,1,2$, and 3 BOS at 1,2, and 3 years after retransplantation. Filled-in bars show proportion of patients in each stage who underwent retransplantation because of $\mathrm{OB}$, as opposed to other indications.

were in New York Heart Association functional class I, $34 \%$ in class II, $10 \%$ in class III, and $3 \%$ in class IV. Fifty-one of the 59 survivors did not require supplemental oxygen whereas 8 patients were oxygen dependent.

Pulmonary function and BOS stages in retransplantation survivors. Complete, up-to-date $\mathrm{FEV}_{1}$ data were available from every retransplant recipient who survived at least 1 year after operation. Fig. 3 shows the prevalence of BOS stages in these patients at 1,2, and 3 years after retransplantation. Seventy-nine percent of all retransplant recipients were free of BOS (stages 1 to 3 ) at 1 year, $64 \%$ at 2 years, and $56 \%$ at 3 years. The prevalence of stage 3 (severe) BOS was $12 \%$ at 1 year, $15 \%$ at 2 years, and $32 \%$ at 3 years after retransplantation, which is similar to that reported after primary lung transplantation. ${ }^{14,19-21}$ With increasing duration of follow-up, patients who underwent retransplantation because of $\mathrm{OB}$ were represented disproportionately in the higher BOS stages, as compared with patients who underwent reoperation because of non-OB conditions (Fig. 3). By 3 years after retransplantation, only $31 \%$ of patients who underwent retransplantation because of $\mathrm{OB}$ were free of BOS versus $83 \%$ of patients who underwent retransplantation for other indications $(p=0.02)$. Subset analyses revealed that the interval between transplant operations in patients with $\mathrm{OB}$ did not influence the prevalence of BOS at $2(p=0.10)$ and 3 years $(p=$ 0.53 ) after retransplantation. As shown in Fig. 4 , the development of severe BOS had a negative impact on subsequent patient survival. Retransplant recipients in BOS stage 3 at 1 year had a significantly worse actuarial survival than those in BOS stages 0 to $2(p<0.01)$.

In the 27 recipients who survived beyond the third anniversary of retransplantation, $\mathrm{FEV}_{1}$ values decreased by $2 \%$ at 1 year, $13 \% \pm 5 \%$ at 2 years $(95 \%$ confidence interval $3.2 \%$ to $22.8 \%$ ), and $19 \% \pm 7 \%$ at 3 years ( $95 \%$ confidence interval $5.3 \%$ to $32.7 \%$ ) versus postoperative baseline values $(p=0.02$ at 3 years). The absolute $\mathrm{FEV}_{1}$ value at 2 years after retransplantation was associated with subsequent survival at $3(p=0.002)$ and 4 years $(p=0.01)$.

Fig. 5 shows the changes in absolute $\mathrm{FEV}_{1}$ values in 27 recipients who were followed up for 3 years after retransplantation. Patients who underwent retransplantation because of $\mathrm{OB}$ had a significant decrease in $\mathrm{FEV}_{1}$ values at $2(p=0.02)$ and $3(p<$ 0.01 ) years relative to the postoperative baseline value, whereas the $\mathrm{FEV}_{1}$ value of patients who underwent retransplantation for other indications did not significantly change. Significant differences between groups were noted at $2(p=0.04)$ and 3 years $(p=0.02)$. Fig. 6 depicts the changes in absolute $\mathrm{FEV}_{1}$ values in patients who received a single-lung versus a bilateral-lung retransplant. Al- 


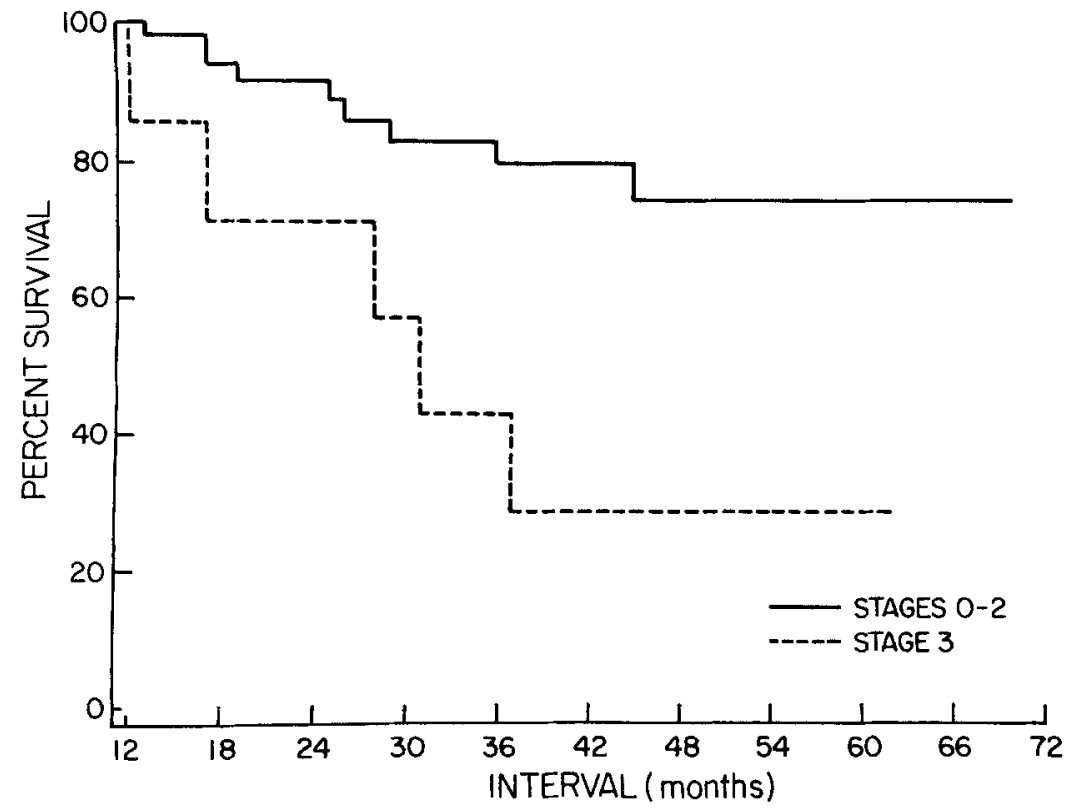

Fig. 4. Actuarial survival of retransplant recipients in BOS stages 0 to $2(n=55)$ versus stage $3(n=7)$ at 1 year; $p<0.01$.

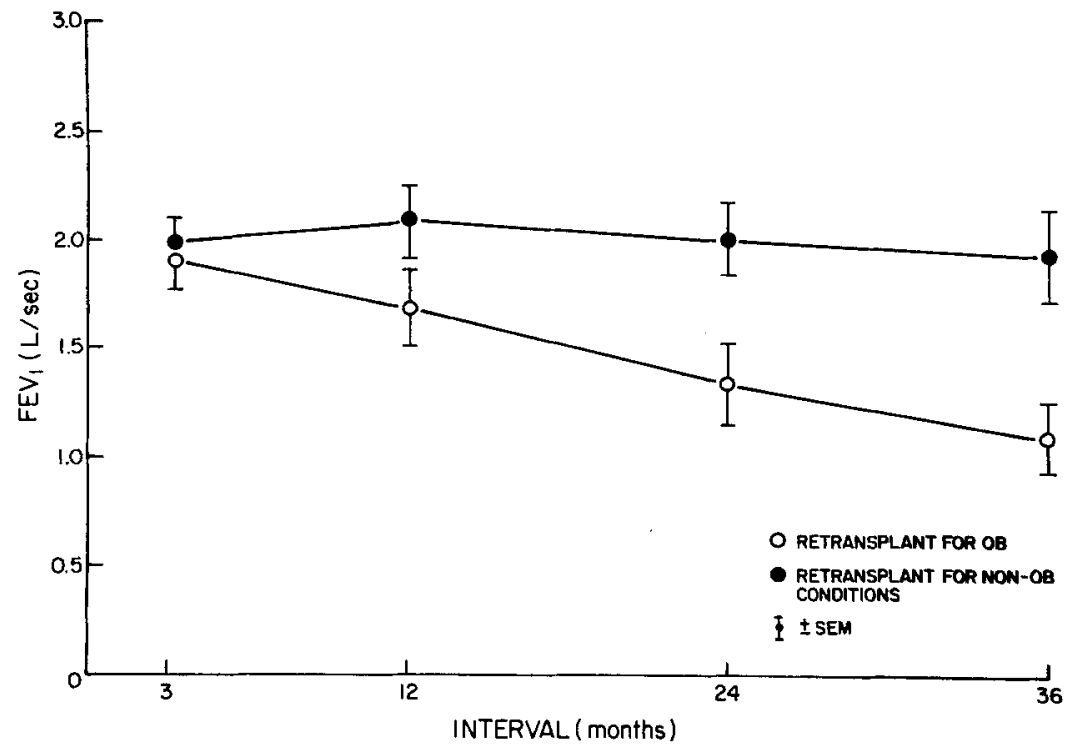

Fig. 5. $\mathrm{FEV}_{1}$ values in 3-year survivors who underwent retransplantation because of $\mathrm{OB}(n=14)$ versus non-OB conditions ( $n=13$ ); see text for $p$ values. SEM, standard error of mean.

though bilateral pulmonary retransplant recipients had a significantly higher $F E V_{1}$ value 3,12 , and 24 months after operation, by 3 years after retransplantation the $\mathrm{FEV}_{1}$ values did not significantly differ between groups $(p=0.35)$.

\section{Discussion}

Despite significant progress in the management of lung donors, ${ }^{1}$ in operative technique, and in postoperative care ${ }^{4}$ in recent years, the practice of lung transplantation remains constrained by a marked 


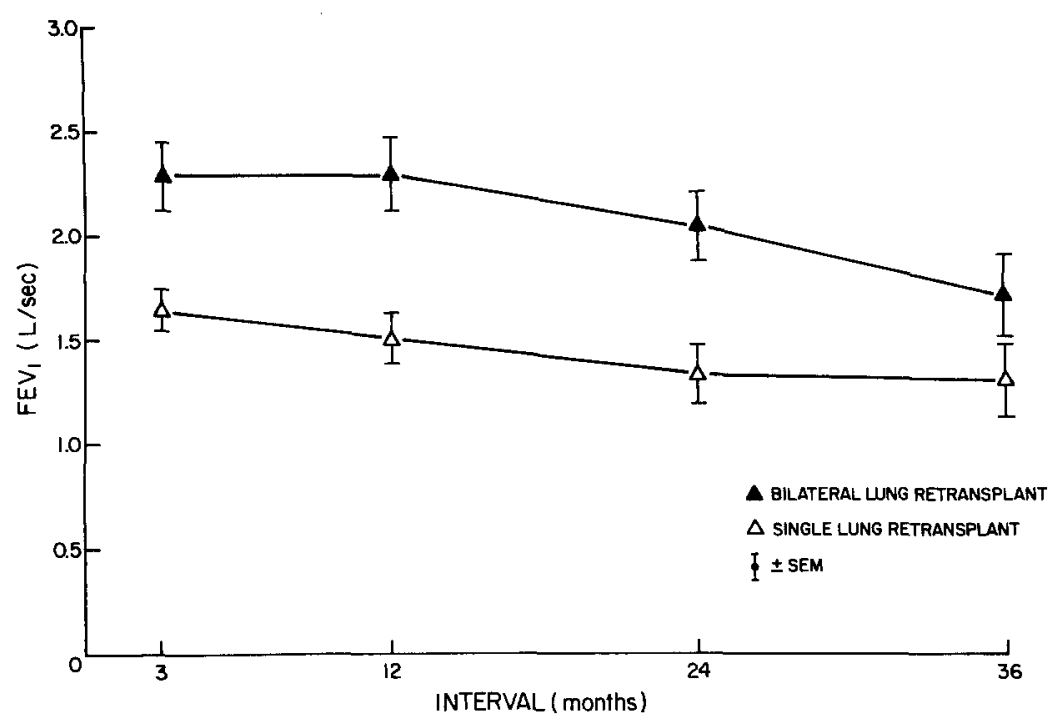

Fig. 6. $\mathrm{FEV}_{1}$ values in 3-year survivors who underwent single-lung retransplantation $(n=14)$ versus bilateral lung retransplantation $(n=13)$; see text for $p$ values. $S E M$, standard error of mean.

shortage of donor organs. The pulmonary retransplant registry was established in 1991 to determine the outcome and predictors of survival after retransplantation and to promote the efficient use of scarce donor organs. Data from the International Society for Heart and Lung Transplantation Registry on more than 1000 single-lung transplant recipients have confirmed that a previous lung transplant increases the risk of 1-year mortality more than threefold. ${ }^{3}$ Many lung transplant programs accordingly do not offer recipients with acute or chronic graft failure the option of retransplantation. Nonetheless, some centers have developed particular expertise in pulmonary retransplantation, with intermediate-term actuarial survival rates only slightly lower than those after primary lung transplantation. ${ }^{11,13,14}$ To make optimal use of scarce donor lung grafts, it is important to determine whether the pulmonary function of surviving retransplant recipients is preserved as well as that in recipients of first-time lung grafts.

Since the previous report from the retransplant registry in $1995,{ }^{8} 21$ new patients have been recruited and the registry database has matured. All patients are currently being followed up prospectively, with 6- to 12-month updates of pulmonary function and clinical status. The median follow-up in surviving patients is now 780 days, versus 630 days in our previous report. Furthermore, the number of 3-year survivors after retransplantation has almost doubled and the number of 4-year survivors has more than tripled. The increasing duration of fol- low-up in retransplantation survivors has resulted, for the first time, in significant differences in BOS stage and $F E V_{1}$ values between patient groups.

Multivariable analyses of 3-month survival have confirmed the cardinal importance of ambulatory status in predicting early outcome after retransplantation. The $32 \%$ of patients who were ambulatory immediately before retransplantation had almost a threefold increased likelihood of postoperative survival. In view of the marked scarcity of donor lung grafts, we therefore believe that lung retransplantation should be limited to ambulatory patients. By single covariate analysis, a longer interval between transplant procedures was associated with increased early survival, consonant with the recently published University of Vienna experience ${ }^{22}$ and the international experience after cardiac retransplantation. ${ }^{3}$ However, this factor was not significant on multivariable analysis, indicating that some of its association with early survival may have been a result of the confounding effects of other variables, such as ambulatory status. Further patient accrual and a longer follow-up of registered patients should provide a more precise indication of the relation of the interval between transplantation procedures to survival after retransplantation.

Recently, the Harefield experience of 27 singlelung retransplantations in patients with $\mathrm{OB}$ has been reported. ${ }^{23}$ The 1-year actuarial survival after singlelung retransplantation was $56 \% \pm 9 \%$, which compares favorably with the $27 \%$ 1-year survival after 
repeat heart-lung transplantation that has been noted in data from the International Society for Heart and Lung Transplantation Registry. ${ }^{3}$ A multivariable analysis of the Harefield data revealed that ambulatory recipients, patients who were not receiving mechanical ventilation at the time of retransplantation, and those who had a long interval between transplantation procedures were most likely to have a good outcome. ${ }^{23}$ These data corroborate the findings of the pulmonary retransplant registry, although in our experience with 160 retransplant recipients the lack of requirement for ventilatory support before reoperation was not significantly related to 3-month survival by marginal or multivariable analysis (Table I).

Because the median duration of follow-up in postoperative survivors was greater than 2 years in our study, a separate analysis was performed to determine the factors associated with and predictive of 2-year survival. As shown in Table I, no recipient variable was predictive of intermediate-term survival; however, when adjusted for a possible center effect, ambulatory status became a significant predictor of 2-year survival. As indicated in Table II, more recent year of reoperation and a total center volume of five or more retransplantation procedures were significantly associated with 3 -month survival. However, the effect of year of retransplantation was less prominently associated with survival than in previous studies. ${ }^{7,8}$ On multivariable analysis, no donor or operative variable was associated with early survival after retransplantation; nevertheless, a total center volume of five or more retransplantation procedures predicted increased 2-year survival. Interestingly, the odds ratio favoring survival in high-volume centers was higher in the 2-year, rather than 3-month, survival analysis (Table II). This illustrates that increasing experience with pulmonary retransplantation is associated not only with decreased operative mortality, but also with increased expertise in patient treatment and improved results in the intermediate term after retransplantation.

Analysis of the pulmonary function and BOS data confirmed that patients who underwent retransplantation because of OB had more significant pulmonary dysfunction in the intermediate term after operation than those who underwent retransplantation for other indications. Because most patient mortality occurred early after retransplantation, actuarial survival was not significantly different between the $\mathrm{OB}$ and non-OB recipients (Table I).
Furthermore, the differences in BOS stage and $\mathrm{FEV}_{1}$ values between $\mathrm{OB}$ and non-OB recipients became apparent only 2 years after operation and were significant after 3 years of follow-up (Figs. 3 and 5). Because retransplant recipients in BOS stage 3 at 1 and 2 years had a significantly worse actuarial survival than those in BOS stages 0 to 2, further patient follow-up may result in significant differences in survival between $\mathrm{OB}$ and non-OB retransplant recipients.

The results of this study indicate that improved management strategies are indeed necessary to prevent the development of progressive graft dysfunction after retransplantation because of OB. Recently, several lung transplant programs have accrued experience with the use of cytolytic therapy $^{24}$ and methotrexate ${ }^{25}$ to treat evolving BOS after primary lung transplantation. Furthermore, the use of tacrolimus, as opposed to cyclosporine, as the main immunosuppressive agent after primary lung transplantation has shown promise, ${ }^{26}$ although a decrease in the prevalence of BOS as a result of tacrolimus therapy has yet to be conclusively demonstrated. Currently, the Hannover group ${ }^{14}$ and other lung transplantation programs are investigating the use of tacrolimus as the principal component of an alternative immunosuppressive regimen after retransplantation. Data on immunosuppressive protocols are being prospectively entered into the retransplant database to determine whether newer agents have an impact on the high rate of recurrent $\mathrm{OB}$ in patients who undergo retransplantation because of this complication. We hope that with improved selection of retransplant candidates, increased experience in reoperative techniques, and the evolution of new immunosuppressive protocols, the results of retransplantation will improve so that actuarial survival after these procedures can approximate that after primary lung transplantation.

\section{REFERENCES}

1. Sundaresan S, Trachiotis GD, Aoe M, Patterson GA, Cooper JD. Donor lung procurement: assessment and operative technique. Ann Thorac Surg 1993;56:1409-13.

2. Novick RJ, Gehman KE, Ali IS, Lee J. Lung preservation: the importance of endothelial and alveolar type II cell integrity. Ann Thorac Surg 1996;62:302-14.

3. Hosenpud JD, Novick RJ, Bennett LE, Keck BM, Fiol B, Daily OP. The registry of the International Society for Heart and Lung Transplantation: thirteenth official report-1996. J Heart Lung Transplant 1996;15:655-74.

4. Cooper JD, Patterson GA, Trulock EP, Washington University Lung Transplant Group. Results of single and bilateral 
lung transplantation in 131 consecutive recipients. $\mathbf{J}$ Thorac Cardiovasc Surg 1994;107:460-71.

5. Novick RJ, Kaye MP, Patterson GA, et al. Redo lung transplantation: a North American-European experience. J Heart Lung Transplant 1993; 12:5-16.

6. Novick RJ, Andréassian B, Schäfers HJ, et al. Pulmonary retransplantation for obliterative bronchiolitis: intermediateterm results of a North American-European series. J Thorac Cardiovasc Surg 1994;107:755-63.

7. Novick RJ, Schäfers HJ, Stitt L, et al. Seventy-two pulmonary retransplantations for obliterative bronchiolitis: predictors of survival. Ann Thorac Surg 1995;60:111-6.

8. Novick RJ, Schäfers HJ, Stitt L, et al. Recurrence of obliterative bronchiolitis and determinants of outcome in 139 pulmonary retransplant recipients. J Thorac Cardiovasc Surg 1995;110:1402-14.

9. Miller JD, Patterson GA. Retransplantation following isolated lung transplantation. Semin Thorac Cardiovasc Surg 1992;4:122-5.

10. Bjortuft O, Forester A, Boe J, Geiran O. Single lung transplantation as treatment for end-stage pulmonary sarcoidosis: recurrence of sarcoidosis in two different lung allografts in one patient. J Heart Lung Transplant 1994;13:24-9.

11. Fournier M, Sleiman $\mathrm{C}, \mathrm{Mal} \mathrm{H}$, et al. Single-lung retransplantation for late graft failure. Eur Respir J 1993;6:1202-6.

12. Adams DH, Cochrane AD, Khaghani A, Smith JD, Yacoub MH. Retransplantation in heart-lung recipients with obliterative bronchiolitis. J Thorac Cardiovasc Surg 1994;107:450-9.

13. Haverich A, Hirt SW, Wahlers T, Schäfers HJ, Zink C, Borst HG. Functional results after lung retransplantation. J Heart Lung Transplant 1994;13:48-55.

14. Schäfers HJ, Hausen B, Wahlers T, Fieguth HG, Jurmann M, Borst HG. Retransplantation of the lung: a single center experience. Eur J Cardiothorac Surg 1995;9:291-6.

15. Harris EK, Albert A. Survivorship analysis for clinical studies. New York: Marcel Dekker, 1991:12-5, 53-62.

16. Hosmer DW, Lemeshow S. Applied logistic regression. New York: John Wiley, 1989:1-134.

17. Cooper JD, Billingham M, Egan T, et al. A working formulation for the standardization of nomenclature and for clinical staging of chronic dysfunction in lung allografts. J Heart Lung Transplant 1993;12:713-6.

18. Armitage P, Berry G. Statistical methods in medical research. 2nd ed. Oxford: Blackwell Scientific, 1987:361-4.

19. Sharples LD, Tamm M, McNeil K, Higenbottam TW, Stewart S, Wallwork J. Development of bronchiolitis obliterans syndrome in recipients of heart-lung transplantation: early risk factors. Transplantation 1996;61:560-6.

20. Egan TM, Detterbeck FC, Mill MR, et al. Improved results of lung transplantation for patients with cystic fibrosis. $\mathbf{J}$ Thorac Cardiovasc Surg 1995;109:224-35.

21. Reichenspurner H, Girgis RE, Robbins RC, et al. Obliterative bronchiolitis after lung and heart-lung transplantation. Ann Thorac Surg 1995;60:1845-53.

22. Wekerle T, Klepetko W, Wisser W, et al. Lung retransplantation: institutional report on a series of twenty patients. J Heart Lung Transplant 1996;15:182-9.

23. Al Kattan K, Tadjkarimi S, Banner N, Khaghani A, Yacoub M. Pattern of survival and functional results of single lung transplantation for obliterative bronchiolitis (abstract). J Heart Lung Transplant 1996;15:S69.

24. Kesten S, Rajagopalan N, Maurer J. Cytolytic therapy for the treatment of bronchiolitis obliterans syndrome following lung transplantation. Transplantation 1996;61:427-30.

25. Niedermeyer J, Hohlfeld J, Hamm H, et al. Immunosuppressive regime with methotrexate in bronchiolitis obliterans following lung and heart-lung transplantation: a prospective study (abstract). Chest 1995;108(suppl):123S.

26. Griffith BP, Bando K, Hardesty RL, et al. A prospective randomized trial of FK506 versus cyclosporine after human pulmonary transplantation. Transplantation 1994;57:848-51.

\section{Discussion}

Dr. Bruce A. Reitz (Stanford, Calif.). This is a further communication from the pulmonary retransplant registry, and the data now are becoming more valuable with the longer-term follow-up that is now available. I think the most encouraging finding of this report is that there is an improving 1-year survival in these retransplantation cases, now at $45 \%$ overall, up from about one third a year ago in the previous report. The current finding of a center effect, namely, that more than five retransplants is related to improved long-term survival, suggests that a learning curve exists. It is not clear to me, however, why this is exactly so. In cardiac transplantation, retransplantation because of early graft failure has always had a much worse prognosis than retransplantation because of coronary artery disease. Can the authors comment on the fact that recipient retransplantation indication was not significant? Is it obscured by the interval between transplants or by relatively fewer retransplants for graft failure being done? Could the learning curve be a result of those centers doing more retransplants developing a better idea of who the ideal candidate should be for retransplantation?

The second important finding is that beyond 3 months, the survival of these patients is close to that of patients with primary transplants. In the late follow-up, the recurrence of $\mathrm{OB}$ in patients who underwent retransplantation because of this indication is disappointing but not surprising. The only progress in the area of OB will come with better immunosuppression; perhaps tolerance induction or some undefined treatment. In this regard, in a model of tracheal transplantation in rats simulating OB in Dr. Morris' lab at Stanford, we have found that both rapamycin and leflunomide are significantly better than cyclosporine or tacrolimus in preventing OB-like lesions. Perhaps the microchimerism being studied at Pittsburgh will also be helpful. Thus we hope the need for retransplantation and these worse outcomes in patients who undergo retransplantation will be improved in future years.

Inevitably the question comes up of whether retransplantation should be done at all because donor lungs are scarce; this point was made earlier, and waiting lists are increasing. Given the results presented, some might conclude that retransplantation should not be done. I personally believe that this is the decision of a local program, with some choosing to offer retransplantation and others not. However, I would like to ask the authors' thoughts on this issue and whether they had queried the 35 centers on their recent or current policies with respect to retransplantation.

Dr. Novick. Thank you, Dr. Reitz. Concerning the issue of retransplantation center volume, we examined each of 
the 17 other variables that we studied, and none of them had an impact on the differing results seen in centers with experience with five or more versus fewer than five retransplantations. We believe that the improved results from the former centers reflect a learning curve, in terms of not only how to safely perform retransplantation procedures but also how to take care of these patients in the intermediate term after operation.

Concerning the issue of alternative immunosuppressive regimens, I believe that this is a key factor. It may well be that patients who undergo retransplantation because of OB should be given one of the newer immunosuppressive agents after operation. Data on immunosuppressive protocols after retransplantation are being collected prospectively in our database, and we await the result of future analyses of these data with interest.

Finally, concerning the appropriateness of pulmonary retransplantation, I believe that the registry results indicate that retransplantation should only be done in select centers with experience in retransplantation. Furthermore, pulmonary retransplantation should be performed in patients who are ambulatory and who are maximally able to benefit from the procedure. In our initial study published 3 years ago we asked each contributing surgeon whether he or she would perform a retransplantation again in these patients; $75 \%$ of the polled surgeons responded in the affirmative.

Dr. Shaf Keshavjee (Toronto, Ontario, Canada). Did the authors analyze the data with respect to survival of singleversus double-lung transplants in retransplantation?

Dr. Novick. Yes, we did. There was no survival difference according to the type of retransplantation procedure that was performed. In $37 \%$ of cases, an old contralateral graft was left in situ after retransplantation. In previous years, this factor tended to be associated with worse survival; however, with an increasing number of patients in the registry, it is now clear that patients with and without an old retained contralateral graft have similar actuarial survival and pulmonary function in the intermediate term after operation.

\section{Appendix: Participating centers}

United States. Stanford University Medical Center, Stanford, Calif.; Loyola University Medical Center, Maywood, Ill.; University of Iowa Hospital, Iowa City, Iowa; Brigham and Women's Hospital, Boston, Mass; University of Michigan Medical Center, Ann Arbor, Mich.; University of Minnesota Health Center, Minneapolis, Minn.; Washington University Medical Center, St. Louis, Mo.; St. Louis Children's Hospital, St. Louis, Mo.; University of North Carolina Medical Center, Chapel Hill, N.C.; University of Pennsylvania Hospital, Philadelphia, Pa.; University of Pittsburgh, Presbyterian Hospital, Pittsburgh, Pa.; Vanderbilt University Medical Center, Nashville, Tenn.; Baylor-Methodist Hospital, Houston, Tex; University of Texas Medical Center, San Antonio, Tex.; University of Virginia Medical Center, Charlottesville, Va.; and University of Wisconsin Medical Center, Madison, Wis.

Canada. Toronto Hospital, Toronto, Ontario; Montreal General Hospital, Montreal, Quebec; and Centre for Health Sciences, Winnipeg, Manitoba.

Europe. Allegemeine Krankenhaus, Vienna, Austria; Hopital Erasme, Brussels, Belgium; Rigshospitalet, Copenhagen, Denmark; Papworth Hospital, Cambridge, England; Freeman Hospital, Newcastle upon Tyne, England; Helsinki University Central Hospital, Helsinki, Finland; Hopital Beaujon, Clichy, France; Centre Hospitalier Universitaire de Grenoble, Grenoble, France; Hopital d'Enfants de la Timone, Marseille, France; Hopital Xavier Arnozan, Pessac, France; Centre Medico-Chirurgical Foch, Suresnes, France; Medizinische Hochschule Hannover, Hannover, Germany; Klinikum Großhadern, Munich, Germany; Academisch Ziekenhuis Groningen, Groningen, Holland; Rikshospitalet, Oslo, Norway; and Universitatsspital Zurich, Zurich, Switzerland. 